\title{
The Construction of Practical Teaching System for Training of Information Management Application Talents

\author{
Yu Lijuan ${ }^{1, a^{*}}$, Dong Shuang ${ }^{1, b}$ and Ren Chengmei ${ }^{1, c}$
}

${ }^{1}$ Department of Information Management and Electronic Business, Beijing Union University, China

agltijuan@buu.edu.cn, bgltdongshuang@buu.edu.cn, oltchengmei@buu.edu.cn

${ }^{\star}$ Corresponding author

\begin{abstract}
The new development of the information technology is a great challenge to information management talents training. It is necessary to adjust the training idea, reconstruct the knowledge structure, re-position the ability training objectives according to new needs, and build a new process system to meet the new needs. In this paper, the ability target of the information management application talents is re-positioned, and the practical teaching system of this kind of talent training is reconstructed. The pattern has been shown to be effective and practical through practice.
\end{abstract}

Keywords: information management; application talents training; practical teaching system.

\section{信息管理应用型人才培养实践教学体系构建}

\section{于丽娟 $1, \mathrm{a}^{*}$ 董爽 ${ }^{1, b}$ 任成梅 ${ }^{1, c}$}

北京联合大学管理学院信息管理与电子商系, 朝阳区, 北京, 中国 agltlijuan@buu.edu.cn, bgltdongshuang@buu.edu.cn, gltchengmei@buu.edu.cn “通讯作者

中文摘要. 信息技术的新发展给信息管理 类人才培养带来了挑战, 需要调整培养理 念, 重构知识结构, 需要根据新需求重新定 位能力培养目标, 构建适应新需求的培养过 程体系。本文重新定位了信息管理类应用型 人才的能力目标, 构建了该类人才培养的实 践教学体系, 通过实践证明了该模式的有效 性和实用性。

关键词：信息管理; 应用型人才培养; 实践教 学体系

\section{1. 引言}

现代信息技术、云计算以及大数据正改 变着人类的生活方式和思维模式,也给管理 带来巨大挑战, 新的管理诉求如搜索服务、 产品推荐、舆情分析等不断出现, 数据的分 析和处理等都要适应大数据的基本特征。这 些变化给信息管理类人才培养带来了挑战, 需要调整培养理念, 重构知识结构, 特别是 能力需求的重新定位以及培养过程等方面 都要适应新的发展需要。 


\section{2. 信息管理类人才的培养目标及能力定位}

应用信息技术实施高效管理是本科信 息管理应用型人才的重要特征, 因此, 该类 人才应是一种懂管理会技术的复合型人才。 懂管理就是懂得基本的管理业务, 能够将现 实中的管理业务用数据或信息加以表达, 将 隐藏在日常业务过程中的管理需求抽象成 数据信息进行挖掘, 并能分析隐藏在数据中 的业务规律, 提供趋势预测, 从而支持管理 决策。会技术意味着能够应用新兴信息技术 和管理方法处理各种复杂的数据和信息, 为 管理目标提供决策支持。

管理信息系统是实现信息管理的重要 平台。在信息技术应用到管理领域的早期, 需要广泛地开发、推广与应用管理信息系 统, 那时本科信息管理应用型人才特别强调 要具备管理信息系统的开发技能, 具备信息 系统运营与维护技能。随着管理信息系统开 发技术的不断成熟, 信息管理类人才的能力 需求逐渐转移到信息系统规划、分析与设 计、运营与维护等。此外随着大数据时代的 到来, 信息管理即数据分析与挖掘的能力越 来越成为本科信息管理应用型人才重要的 能力需求。

国内本科信息管理类人才培养集中在 信息管理与信息系统专业以及相关信息技 术类专业。通常的专业培养目标是: 培养具 备现代管理科学及信息管理学的理论知识, 具备较强的计算机应用能力, 掌握系统思想 和信息系统的分析与设计方法, 具备数据分 析与挖掘能力, 能在各级管理部门、工商企 业、金融机构、科研单位等从事信息管理及 系统建设与应用工作, 从事数据分析与处理 工作的高素质专门人才。这一目标即包括了 管理信息系统相关的能力, 又包括了数据分 析处理相关能力。

由此，培养信息管理应用型人才仍以管 理信息系统为主线, 深化管理与技术的融 合, 既可实现具有较强管理业务能力, 又可 实现具备信息系统建设与应用技术能力的 复合型人才的培养目标, 确定以管理信息系 统分析与设计、运营与维护为核心能力目标 之一。实现信息管理目标还涉及信息技术与 管理方法的应用, 突出数据处理与数据挖掘 能力的培养目标, 确定数据处理与分析能力
为核心能力目标之二。为达到以上核心能力 目标, 信息管理应用型人才还应具备一定的 基本能力, 能力目标定位如图1所示。

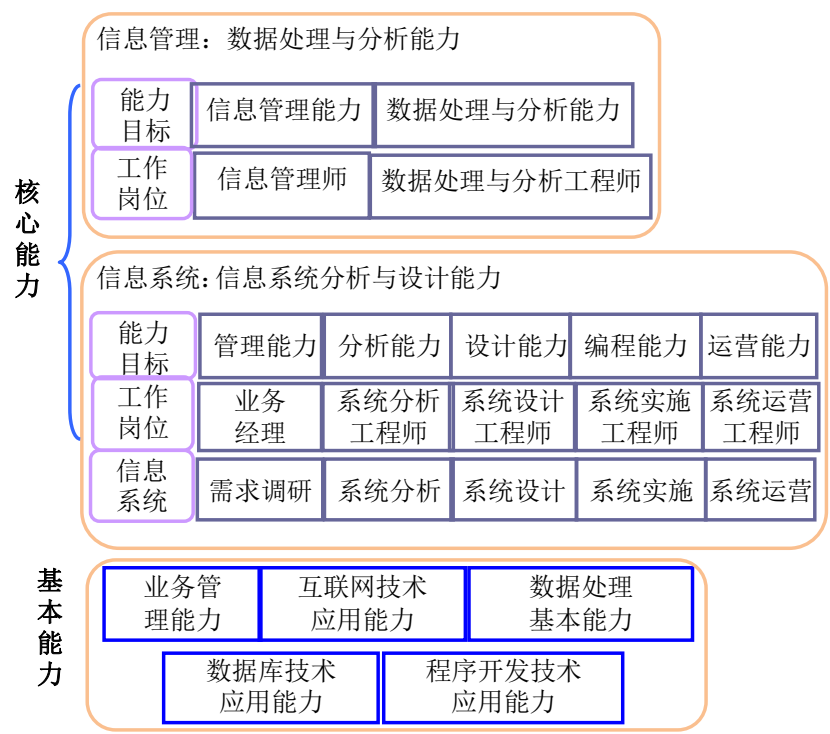

图1 专业能力目标定位

\section{3. 信息管理应用型人才培养实践教学体系 构建}

\section{1实践教学体系构建}

本科信息管理应用型人才是综合素质 和谐发展的较高层次的人才类型, 工作中以 信息技术的应用为重要特征, 因此培养过程 应更加重视能力培养和素质提高, 不仅要有 一定决策、管理、方案设计等实践操作能力, 还要有较强的创新、创业能力, 需要构建一 套选修与必修相结合的专业实践教学体系。 因此信息管理应用型人才培养实践教学体 系分为两条主线, 一是专业实践体系, 二是 素质拓展体系, 两者相互促进。专业实践体 系是应用性人才培养的必修环节, 每环节学 生要完成相应的学习或工作任务, 基于这些 工作任务, 学生可以选择参加社会调查、分 析与研究等多层次, 多类型的素质拓展项 目, 从而有效地支持了学生创新创业能力和 各种综合能力的培养, 使学生的专业技能即 有广度又有深度地得到训练。构建的实践教 学体系见图2所示。

\section{2专业实践体系}

结合人才能力递进增长的规律, 构建系 列必修的实践教学体系，该体系以 “认识实 
践一>课程实践一>专业综合实践 $\longrightarrow$ 毕业 实践” 为主线, 各环节以课程为基础, 设置 有课内实践和独立实践, 选修与必修等多种 形式。

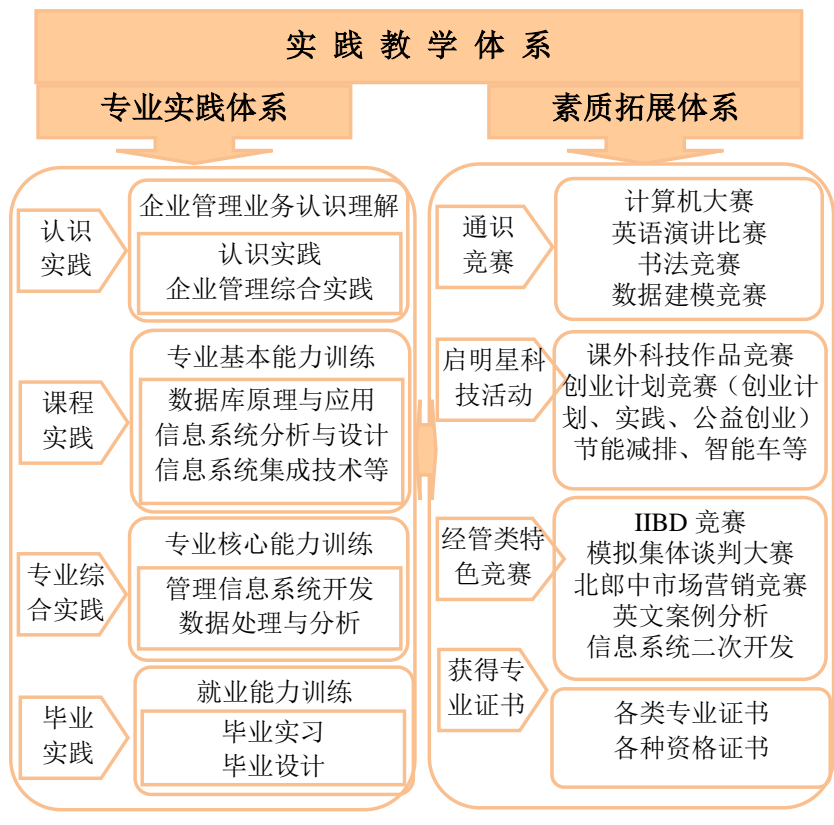

图2 实践教学体系

\subsection{1 认识实践}

设置企业管理综合实践和认识实习两 门课程。企业管理综合实践是ERP沙盘模 拟、软件模拟实践, 要求学生完成经营管理 业务报表, 或竞争管理决策, 使学生体验经 营管理的业务流程, 参与竞争模拟, 从而能 够充分认识和理解经营管理业务。认识实习 安排在校外实践基地, 组织学生到企业参观 生产流程、管理业务流程、企业信息化建设、 信息化运营与维护, 使学生感受企业对人才 知识和能力的需求, 激发学生的学习热情。

\subsection{2 课程实践}

信息技术类课程一般都设有课内实践 和1-2周独立的课程设计。课内实践主要验 证课程学习的理论知识, 并能应用技术方法 解决相关的问题。对于核心能力培养的技术 类课程设置独立的课程设计, 通过综合应用 课程的知识、方法和技术, 解决较为综合的 实际问题。独立实践是课程知识综合应用的 技能训练, 是专业基本能力培养的重要途 径。

\section{2 .3 专业综合实践}

是独立设置的实践课程, 采用多样化模 块化教学实践, 与企业共建教学内容, 每模
块与一个或多个特定企业合作, 结合企业所 涉及的区域和行业特点, 要求学生解决更加 综合的实际问题, 完成实践任务。学生可根 据就业方向、兴趣爱好选择和强化自己的专 业实践能力, 从而更加适应现代新技术新发 展对人才能力提出的新要求。

\section{2 .4 毕业实践}

包括毕业实习和毕业设计两个阶段。一 般是推荐学生到企业参加岗位工作实践, 参 加企业的真实项目，企业新员工培训项目。 毕业实习是专业能力培养与社会需要接轨 的重要环节, 试图拉近学生能力与社会需求 的距离, 一般由实习企业安排工作任务并完 成考核。毕业设计是大学教育的最后环节, 对学生的综合知识应用能力、拉近与企业人 才能力需求的距离具有重要意义, 学生可根 据实习情况、就业方向及专业方向选择毕业 设计题目，独立完成考核目标。

\section{3素质拓展体系}

素质拓展以学生科技活动为主, 结合专 业实践教学, 高校或企业组织的各类学科专 业竞赛、学术交流, 创新创业实践等, 鼓励 学生参加各项科技活动、发表论文、撰写研 究报告、获得职业资格或技能证书, 使学生 在专业教育阶段得到创新性科学研究或技 术研发的初步锻炼, 培养技术开发或科学研 究的兴趣和能力。学生科技活动按性质划分 可以分为四类:

\subsection{1通识竞赛}

包括计算机大赛、英语演讲比赛、书法 竞赛、数学建模竞赛等。

\subsection{2 “启明星” 科技活动}

包括大学生科技创新项目和大学生科 技竞赛两部分。大学生科技创新项目历时 1 年, 主要开展科学调查、分析、研究, 并要 有相应的科研成果。大学生科技竞赛一般归 为 “启明星” 大学生科技竞赛平台, 对接高 校的 “挑战杯” 赛事, 包括大学生课外学术 科技作品竞赛和创业计划竞赛两部分, 并按 单双年分别开展。创业计划竞赛属于 “创青 春” 系列赛事, 包括创业计划竞赛、创业实 践竞赛、公益创业竞赛。此外大学生科技竞 赛还包括节能减排、智能车等各项赛事。 


\subsection{3 经管类特色活动。}

包括IIBD竞赛校级选拔赛、全国高校模 拟集体谈判大赛、英文案例分析大赛、信息 系统二次开发等。

3.3.4获得专业证书

素质拓展体系还包括鼓励学生通过自 身努力获得由各类组织、公司颁发的专业证 书, 职业资格证书, 如企业助理信息管理师 资格证书等。

\section{4. 实践教学体系保障}

为使实践教学得以高质量实施, 不断提 高实践教学质量, 需要一系列保障措施。

\section{1 校企合作}

校企合作是支持实践教学体系实施的 重要保障, 应与企业共同设计教学方案和实 践内容, 共建校内外实践基地, 共同开展教 学, 并试图基于合作企业涉及的专业区域和 产业依托, 以及合作企业的业务范围特色, 在开展实践教学的同时突显本科信息管理 应用型人才培养的专业特色。

校外实践基地主要建立在长期稳定的 合作企业中, 企业提供学生参观、学习的机 会, 提供学生实习项目、岗位任务, 负责培 训、培养人才, 以使学生能够胜任一定的岗 位工作任务, 增强就业力, 对于优秀学生负 责推荐就业或留用。专业实践体系中的认识 实习和毕业实习主要在校外实践基地实施。 校内实践基地建设主要引进企业信息化开 发平台、软硬件技术等教学资源。适合信息 管理应用型人才培养的教学资源例如用友 的ERP-UAP, 八百客SaaS平台, 管理信息系 统开发案例, IT项目驱动实训平台, 小型企 业管理应用软件等。这些教学资源用于开展 校内课程实践, 如企业管理综合实践、各类 课程实践和专业综合实践。此外还可引进企 业技术人员, 请他们到学校培训或讲座企业 技术平台、信息技术前沿与专业知识、信息 化人才社会需求与职场规划等。引进的企业 技术人员还可与教师共建实践课程, 针对企 业的技术和开发平台, 建设相适应的实践教 学内容。

\section{2 教师培训}

教师是实践教学体系实施的重要保障。 一方面可以通过校企合作加强师资培训, 如 派教师到企业参加较长期的岗位工作实践, 参加企业组织的各种培训, 组织教师和企业 技术人员合作开展科学研究, 争取企业委托 的科研立项。另一方面可以利用人才强教项 目, 组织教师参加各类培训。信息管理实践 教师培训业界较有名的如高级企业信息管 理师，信息资源规划工程师，客户关系管理 师, 数据挖掘及应用技术工程师, 软件测试 高级工程师等。

\section{3 制度保障}

由于素质拓展体系是选修环节, 需要制 度激励以保障学生积极参与。可以建立导师 制度, 学生进入大二后就分配给指导教师, 由教师负责指导学生的科技实践, 教师可以 结合自己的科研方向, 敦促学生参加科技活 动, 使学生逐步形成较稳定的发展方向, 并 在方向上深入学习、实践和研究, 从而提高 学生的专业技能。也可以结合专业实践各环 节, 从专业层面组织学生参加各类各级别的 科技竞赛, 对于获得全国性科技活动及竞赛 优胜名次的, 或获得各类专业证书的, 可视 与课程关联, 与创新创业能力培养等的关 系, 经相关部门认定后可替代学分, 或给予 经费资助等多种鼓励。

\section{4 课程建设保障}

实践课程是实践教学体系的根本保障。 课程本着扎实基础, 增强知识应用能力, 增 强方向专业技能和创新能力, 提高综合素质 的思路建设和整合教学资源, 内容上要做到 精选和高起点, 教学方法方面要探索适应学 生特点的方法, 如任务驱动、案例教学等, 可通过网络学堂构建网络化、互动式的方法 体系。

实践教学体系是一个不断实践、完善和 优化的过程, 需要定期研讨和重构, 不断总 结存在的问题, 提出今后的改革方案, 从而 不断优化实践教学体系。 


\section{5. 结束语}

该实践教学体系是我校信息管理与信 息系统专业实践教学体系逐渐优化的结果, 从近 5 年培养的毕业生能力看, 学生的创新 创业能力、专业核心能力和可持续发展能力 都得到了明显的提高, 大大提升了学生的就 业竞争力。

\section{References}

[1] Shen Qi, Zhang Yan, Luo Yang, Construction and reform of application-oriented undergraduate practice teaching system, Experimental Technology and Management, Vol.27, pp. 36-38, 2010

[2] Professional Teaching Guidance Committee of management science and Engineering Discipline of education ministry, China Association of International Information Systems (CNAIS). The curriculum system of China information system subject 2011, Tsinghua University press, 2011

[3] LIANG Chang-yong, GU Dong-xiao, LI Xing-guo, YANG Shang-lin, Exploration and Practice of the Reform of Undergraduate Education of the Specialties of Information Management, Journal of Higher Education Research, Vol.31, pp.64-66, 2008

[4] Long Zhaoyang, Tian Chengcheng, Research on the construction of ROPT teaching mode of application oriented Talents Cultivation in information management, Research on Library Science(theoretical version), No.6, pp.12-15, 2011 